\title{
Environment Potential and Adjusting of Gross Domestic Product to the Safe Industrial Development
}

\author{
Michal Cehlár ${ }^{1,}{ }^{*}$, Zou Liang ${ }^{2}$, Lian $\mathrm{Wan}^{2}$, Khanindra Madauri ${ }^{3}$, and Sergey Krysin ${ }^{4}$ \\ ${ }^{1}$ Technical University of Kosice, Faculty of Mining, Ecology, Process Control and Geotechnologies, \\ Letná 9, 04200 Kosice, Slovak republic \\ ${ }^{2}$ Qilu University of Technology, 250353 Daxue Rd, 3501 Shandong, China \\ ${ }^{3}$ Visvesvaraya National Institute of Technology, 440010 South Ambazari Road, Nagpur, India \\ ${ }^{4}$ T.F. Gorbachev Kuzbass State Technical University, Surveying and Geology Department, 650000 \\ Vesennya st. 28, Kemerovo, Russian Federation
}

\begin{abstract}
The importance of the natural resource and environmental factors in the development of the modern economy is becoming more important in the context of energy security and the quality of economic growth. This is also due to the fact that the state's policy in increasing GDP has been adjusted to a qualitative social-and-economic development. In this regard, the quantitative measurement of the quantity and quality ratio of economic growth is relevant. The rise of the global economy as a whole and its individual territories is due to both a high-tech breakthrough and the development of raw materials industries - oil, gas, coal and metallurgy. Currently, to meet the needs of society in natural resources, environmental goods and services, ever-increasing costs are required for expanded reproduction of the mineral resource base and compensation for negative consequences resulting from the degradation of ecological systems and pollution of the natural environment.
\end{abstract}

\section{Introduction}

Thus, natural resources and their territorial combinations, satisfying the numerous and diverse human needs, have a value, the definition and consideration of which becomes an obligatory and important component of the process of making social-and-economic and political decisions. At the same time, the final effectiveness of the use of natural resources depends not only on the total quantity of the resources, but also on their social-andeconomic assessment, the level of substantiation for the effectiveness of their use, including the distribution of natural resources between various alternative using spheres, as well as the effectiveness of the societies' economic and administrative incentives. However, when calculating the value of GDP or GRP, the cost of irretrievably disappeared fuel and energy resources and the external costs in the form of environmental damage to the territories and health of the population are not taken into account.

\footnotetext{
* Corresponding author: juraj.janocko@tuke.sk
} 
It is clear that the inclusion of an assessment of the natural resource and environmental potential in the macroeconomic indicators will lead to a significant adjustment of the current understanding of the level of social-and-economic development of countries and regions, as well as the opportunities which they have to ensure the sustainable well-being of their citizens. At the same time, it is important to understand that neither the abundance of natural resources nor the favorable geographic location of the region automatically guarantees stable rates of such development, high level and quality of life of the population. For example, Russia in terms of the explored reserves of mineral raw materials, timber and other resources occupies the leading place in the world. More than 20 thousand mineral deposits are discovered and explored here. In terms of per capita, Russia's natural and resource potential is 2-2.5 times higher than in the USA, 6-8 times higher than in Germany and 18-20 times higher than in Japan. At the same time, in terms of GDP per capita and the quality of life, it is significantly inferior to all developed countries [1]. In these countries, the main economic resource and means of production is not capital and natural resources, but accumulated knowledge, the level of education, the quality of production processes' organization and ways of selling products.

In this regard, it is urgent to consider the problems of preserving the environment "from above", from macroeconomic positions that allow determining the main causes of environmental degradation. It is necessary to identify those economic directions that affect the environment. This approach is especially relevant for the regions and countries that have a specialization in raw materials. Actually, targeted economic measures aimed at preserving nature will not have an effect without an ecologically balanced macroeconomic policy.

\section{Materials and Methods}

Of particular importance, from the point of view of the adjusting methodology of macroeconomic indicators to the value of natural potential depletion, is the system of ecoeconomic accounting, proposed by the statistical department of the UN Secretariat in 1993. That is the system of "green" national accounts, where the relationship is expressed by linking the adopted system of national accounts, taking into account environmental factors and natural resources described in the works of J. Dickson, J. Backcas, C. Hamilton and others. In the publication "A New Look at the Wealth of Nations" under the auspices of the World Bank, the concept of "true savings" was proposed [2]. This indicator is the result of correction of gross domestic savings, i.e. gross accumulation. Based on these methods, calculations for individual countries showed a huge discrepancy between traditional economic indicators and environmentally adjusted ones. Thus, for many countries in the world, the situation is urgent when, along with formal economic growth, environmental degradation occurs, and environmental correction can lead to a significant reduction in traditional economic indicators, even to negative values of their growth. This situation is typical for Russia with its huge scale of degradation and depletion of natural resources, pollution of the environment.

The concept of "true savings" is closely connected with a new approach to measuring the national wealth of countries. The World Bank calculated the values of natural, produced (physical or artificial) and social capital, as well as their share in the country's total national wealth. Thus, the share of natural capital in national wealth on average for more than 100 countries of the world is $2-40 \%$, the share of human capital is $40-80 \%$. In addition, in developed countries, the share of natural capital in national wealth does not, on average, exceed $10 \%$, while the share of human capital is more than $70 \%$. For many low-income per capita countries, the share of the agricultural component in natural capital is $80 \%$, while in high-income countries this figure does not exceed $40 \%$ [3]. 
The System for Integrated Environmental and Economic Accounting (1993) proposed by the Statistical Division of the United Nations Secretariat, is aimed at taking environmental factors into account in national statistics. This system describes the relationship between the state of the natural environment and the economy of the country. The relationship is expressed by linking the UN system of national accounts (SNA, 1993), taking into account environmental factors and natural resources [4]. "Green" accounts are based on adjusting traditional economic indicators at the expense of two values: the valuation of depletion of natural resources and the environmental and economic damage from pollution. The environmental transformation of national accounts is based on such indicator as an environmentally adjusted net domestic product (EDP):

$$
E D P=(N D P-D P N A)-D G N A
$$

where EDP is an environmentally friendly, clean domestic product;

NDP is a net domestic product;

DPNA - valuation of depletion of natural resources; DGNA is the cost estimate of environmental damage.

According to preliminary estimates by the United Nations Statistics Division, the average EDP is about $60-70 \%$ of GDP [5].

The World Bank proposed and calculated for the countries of the world the "true savings" (genuine (domestic) savings) [6].

$$
G S=(G D S-C F C)+E D E-D P N R-D M G E
$$

where GS is an indicator of true savings;

GDS - gross domestic savings;

$\mathrm{CFC}$ - depreciation of production assets;

EDE - expenditure on education;

DPNR - the amount of depletion of natural resources;

DMGE - damage from environmental pollution.

All values used in the calculation are taken as a percentage of GDP (GDP). The world average level of true savings in 1997 was estimated by the World Bank at 13.6\% of GDP, while gross domestic savings were estimated at $22.2 \%$ of GDP. For Russia, this indicator shows a negative rate of savings and savings ( $-1.6 \%$ of GDP for true (domestic) savings versus $24.7 \%$ of GDP for gross domestic savings in 1997) [7].

The calculations based on these methods for individual countries showed a huge discrepancy between traditional economic and environmentally adjusted indicators. Thus, for many countries in the world, the situation is urgent when, with formal economic growth, environmental degradation occurs, and environmental adjustment can lead to a significant reduction in traditional economic indicators, even to negative values of their growth. This situation is typical for Russia with its huge scale of degradation and depletion of natural resources, pollution of the environment.

\section{Results and Discussion}

The most important thing for the sustainable growth of the region's economy, its entry into the global process of economic globalization and improvement of the quality of life of the region's population is the accentuated implementation of the structural and innovative component in practice and, consequently, the process of diversification of the region's economic development. Without these (major) transformations, neither the first, nor the second, nor the third one is possible. 
The resource-producing territories need not structural reorganization in itself, not innovative transformations by themselves, but they need a significant improvement in the quality of life of the population

The permanent increase in the extraction of mineral resources, from macroeconomic point of view, ensures the growth of the economy, but does not ensure its quality. Therefore, priority was given to solving not only economic, but environmental and social problems, mainly to control social tension and mitigate conflicts.

It is possible to invest huge sums in environmental protection, but without taking into account and correcting the development of the entire economy and its sectors (fuel and energy, metallurgy, agrarian, etc.), the effect of such costs will be minimal.

"True savings" are calculated as the difference between net savings and the sum of all rents for the extraction of natural resources. To calculate the mining rent only energy sources (coal) were taken. Depletion of mineral resources (coal reserves) in monetary terms represents the multiplication of production volumes by the world average cost of 1 ton of coal in US dollars minus production costs. As a result, depletion of subsoil only due to coal mining reduces the cost of GRP by more than $10 \%$ per year. Depletion of forest resources can be defined as zero, since the annual allowable cut is used no more than $3 \%$, i.e. there is no depletion of reserves. In our opinion, this is not a very good criterion, because the underutilization of the estimated cutting forest area creates other problems due to the aging of wood reserves, increased fire risk and tree diseases due to aging. The forest as a result loses its technical properties and creates a significant lost profit from its underutilization. Perhaps in future, this may be taken into account in calculating "true savings", as a result of underutilization of forest resources.

In extracting countries with their huge scale of degradation and depletion of natural resources, pollution, the situation may become urgent when formal economic growth is accompanied by ecological degradation and, ecological correction can lead to a significant reduction in traditional economic indicators, down to negative values of their growth. All these are typical signs of "anti-sustainable" trends in development. The indicators of "true savings" reflect a broader understanding of sustainability, assessing changes in natural resources and environmental quality in addition to productive assets.

The modern economy of extracting countries lives "in debt" with future generations. First of all, this is depletion of mineral resources, depopulation and short life expectancy of the population, accumulated or past environmental damage in the form of disturbed and contaminated land, as well as degraded ecosystems.

In the process of calculating "true savings", a number of assumptions and limitations arose, primarily related to the inadequacy of official statistics and the absence of generally accepted methods for calculating damages, demographic investments, etc. This should be mentioned in particular. The depletion of the mineral resource base was calculated only by coal, as the most significant resource for the region. Accounting for depletion of iron ore, gold, building materials, etc. would further reduce "true savings". The damage from pollution can be accounted in several ways. First of all, it can be done in the form of reducing the production assets cost (metal corrosion, collapsing building materials) due to an aggressive environment, due to contamination with various chemical compounds. In addition, crop losses due to acid rain and soil disturbance. Environmental factors (erosion, loss of humus, acidification of soils, etc.) can reduce the yield of crops to $40 \%$.

In this case, the pollution damage was calculated only by the greenhouse gas emissions calculated from the official statistics on underground coal mining. Damage was calculated on the basis of the cost of global damage $\$ 20$ per 1 ton of greenhouse gases in the equivalent of $\mathrm{CO} 2$. As is known, with open coal mining, methane emissions are not accounted for and therefore the damage should at least double, as more than half of the coal in the region is extracted by open method. 
The calculation of "true savings" can be expanded by categories of resource depletion and environmental degradation. These categories will shift the indicators of "true savings" downwards, increasing their negative value and, accordingly, de-capitalization as a whole. The practical importance of measuring "true savings" is quite clear: constantly negative rate of savings should inevitably lead to deterioration in well-being. For decision-makers, the link between sustainable development and the rate of true savings means that there are many possible ways of influencing for sustainability enhance, from macroeconomic to purely ecological. In any case, the indicator of true savings can be one of the universal aggregate indicators of sustainable development and the quality of economic growth, both for the region and for the country as a whole.

The long-term perspective of solving the problem of sustainable industrial development must be based on:

- increasing the efficiency of materials use in production processes;

- introducing less material-intensive processes and products;

- introducing low- and non-waste technologies;

- preserving and "enlarging" the renewable natural resources.

Rational use of raw materials and resources can lead to savings in investments in the extractive and processing industries from two to four times.

In recent years, investments and operational costs for monitoring and protecting the environment have increased in the region - the "end of pipe" principle is being implemented, that is, the installation of emission trapping devices behind the furnace or unit "at the end of the pipe". At the same time, the acuity of recycling wastes and secondary pollution problems has become urgent. This trend has forced the governments and industries of developed countries to reorient their activities from policies and programs "respond and cure" to "anticipate and prevent". This approach focuses on low-waste technologies, as well as on "zero waste" technologies. This approach to safe industrial development has gained considerable momentum as a result of the adoption of the Declaration of the Economic Commission for Europe on low and non-waste technologies, return for use and recycling of waste (1979) and developed in the Environment Safety Industrial Development (ESID) program adopted by the UN General Assembly in 1987 (resolution 42/187). In this regard, the understanding of the expediency of integrating resource-saving and environmental technologies in production processes from the extraction and processing of primary and secondary raw materials to the production and sale of finished products has come.

The waste reduction is facilitated by the use of technological processes in which little or no waste is formed. This is a difficult condition. At present, another approach to solving the zero waste problem is wastes recycling and their processing, when wastes are used for manufacturing goods that have consumer properties no worse than those obtained from primary raw materials. In this case, there are no wastes at the end of the technological cycle, since some products are manufactured from them. Such a technology can be called "quasi-waste-free".

The handling industrial waste is the key to promoting the region towards sustainable development. The concept of sustainable development has a direct economic and technological rationale, the essence of which can be described with "five R":

Reduction - reducing energy and material consumption;

Replacement - the replacement of non-renewable resources by renewable;

Recovery - recovery of the used resource;

Recycling - processing, recirculation;

Reuse - multiple use of the product. Sustainable development of the region will become a reality with stabilization of the population, food production without depletion of soil and water resources, use of waste, clean energy, transition to energy and resource-saving 
lifestyle. The experience of economically developed countries shows that it is possible to solve the problem of using industrial waste if all the stages of waste movement from the source of their formation to the storage, processing and / or disposal points are regulated simultaneously. Taking into account the fact that only $2 \%$ of consumed mineral resources are converted to final products and the remaining $98 \%$ represent waste.

\section{Conclusion}

Waste management should be based on the implementation of a hierarchical approach: the main priority is given to avoiding waste (non-waste technologies), then there is a choice that if they are formed, it is necessary to strive for their minimization (low-waste technologies), then the possibility of manufacturing from waste (secondary raw materials) of finished goods, the next level is the treatment of waste for the purpose of energy recovery while minimizing secondary waste, and finally, the disposal of waste.

\section{References}

1. L. J. Richardson, R. Cleetus, S. Clemmer, J. Deyette, Environ. Res. Lett., 9, 024006 (2014)

2. N. P. Ivatanova, Ecology-economic assessment of the raw mineral potential of the regions (MSU, Moscow, 2000)

3. Z. Kutlina-Dimitrova, Chief Economist Note, 3, 96-105 (2015)

4. J. G. Fernald, C. I. Jones, American Economic Review, 104(5), 44-49 (2014)

5. S. Zhironkin, M. Gasanov, G. Barysheva, E. Gasanov, O. Zhironkina, G. Kayachev, E3S Web of Conferences, 21, 04002 (2017)

6. A. A. Pugacheva, Scientific Bulletin of Moscow State Mining University, 11, 58-63 (2013)

7. V. Trifonov, O. Loyko, D. Nesteruk, S. Zhironkin, E. Strekovtsova, AIP Conference Proceedings, 1800, 050009 (2017) 